3 The notion that some groups of algae suffer from a "low-morphology problem" that masks their true species diversity has been recognized for at least two decades (van Oppen et al. 1996). This problem has become dramatically evident in recent years as DNA sequence data have taken center stage in species delimitation. The issue is usually associated with algal groups having simple morphologies and a limited set of morphological characters useful for morpho-taxonomic circumscriptions and in taxa experiencing habitat-induced phenotypic plasticity (Verbruggen 2014). The Cladophoraceae, a family of small filamentous green seaweeds, is clearly impacted by the lowmorphology problem and is an excellent example to illustrate these difficulties. The paper of Boedeker et al. (2016) published in this issue represents a milestone in the systematic biology of this widespread group of chlorophytes. The authors propose a new classification of the Cladophoraceae based on a robust molecular phylogeny. The impressive sampling effort and geographical coverage lead to strong conclusions, making this study a major taxonomic advancement for green algae in general, not just the Cladophoraceae.

The Cladophoraceae contains three genera that are familiar to most marine biologists: Cladophora, Chaetomorpha, and Rhizoclonium. They all have thalli consisting of uniseriate filaments formed by large multinucleate cells. The distinction between genera is (apparently) straightforward: Cladophora has branched filaments, Chaetomorpha has unbranched thick filaments, and Rhizoclonium has unbranched thin filaments. In the field, algae of these genera are generally easy to recognize as green filamentous patches, bushes, or rope-like structures occurring in a wide range of habitats (Fig. 1). The Cladophoraceae is one of the few algal taxa that has crossed the borders between sea and freshwater, because it includes species distributed in marine, brackish, and freshwater environments (e.g., in the Mekong river in Laos, where Cladophora is harvested for consumption). Some species thrive in marine intertidal habitats and coastal lagoons, where they occasionally produce large blooms in situations where nutrients are abundant and competition is reduced (Zulkifly et al. 2013). From a geographic point of view, the family has a cosmopolitan distribution, ranging from tropical to polar waters, with generally higher diversity in temperate regions.

The Cladophoraceae is one of the longest-known and studied taxa of green algae (the first few species were described as early as the late $18^{\text {th }}$ century), yet are still recognized as a taxonomically challenging group. Species delimitation has been particularly problematic, as demonstrated by the This is the author manuscript accepted for publication and has undergone full peer review but has not been through the copyediting, typesetting, pagination and proofreading process, which may lead to differences between this version and the Version of Record. Please cite this article as doi: 10.1111/jpy.12459 
plethora of specific and intraspecific names that exist (1,072 listed in AlgaeBase only for Cladophora, Guiry \& Guiry 2016). A poor understanding of the biology of these algae has contributed to this nomenclatural inflation. It is now known that thallus morphology is greatly affected by phenotypic plasticity related to environmental conditions (Leliaert \& Boedeker 2007) and that this has been the major cause of taxonomic misinterpretations. Some morphological characters considered taxonomically relevant may vary in relation to habitat. An excellent example is found in one of the most detailed treatments available for this group: the monograph of van den Hoek (1963) for European Cladophora. This study, which is still considered a key reference for the family, reports that several common Cladophora species exhibit different apical cell sizes depending on whether the alga grows in well-lit or shaded sites, yet apical cell size used to be an important taxonomic character. At the same time, the shortage of morphological characters available for these algae poses a limit to the number of species that can be diagnosed on a morphological basis. It is therefore not surprising that convergent evolution of morphological traits has been common in the Cladophoraceae; this phenomenon emerged in early molecular studies of the family (Bakker et al. 1994, Hanyuda et al. 2002, Leliaert et al. 2003) and is now confirmed with more substantial evidence.

The study by Boedeker et al. (2016) is an example of good practice in the establishment of a natural classification of a taxonomically difficult group of algae. The authors use sequences of the LSU and SSU rDNA genes obtained from a large number of species to infer a robust molecular phylogeny that is then used to update the classification of the family. The number of samples used and the geographic coverage of the study are among the largest seen in a phylogenetic study on macroalgae, resulting from years of extensive collections made by the authors or received from collaborators, and the sequence data are analyzed with sound, state-of-the-art phylogenetic methods.

Not unexpectedly, the study provides definitive evidence that none of the three main genera, Cladophora, Chaetomorpha, and Rhizoclonium is monophyletic. This also suggests that a complete overhaul of the classification of the group is needed. A factor complicating this matter is that several old taxon names exist that are now considered synonyms of these genera, which need to be considered in naming the groupings resolved in the phylogenies. In situations like this, uncertainty about which clades should receive which names often abounds and can lead to decision paralysis. Clearly, such paralysis represents a huge impediment for the establishment of a correct nomenclature and its applications in algal biology and marine ecology. In theory, the logical solution to this problem would be to sequence type specimens, the only ones to which taxonomic names are unambiguously linked. This approach has become increasingly popular in recent years (especially for red algae) and it is likely that high-throughput sequencing methods will make it part 
of the core toolkit for algal taxonomy (e.g., see Hughey et al. 2014). At present, however, obtaining sequences from old herbarium specimens is still a very laborious and error-prone procedure for which there is no guarantee of success. In reality, it is often necessary to go down a more pragmatic path, letting experts familiar with the biology of the group link taxonomic names and molecular groupings by examination of type specimens and consideration of the original descriptions. This is the approach adopted by Boedeker et al. (2016), and we praise them for being decisive in the face of uncertainty and assigning names to seven monophyletic genera: in addition to redefining Cladophora, Chaetomorpha and Rhizoclonium, they describe the new genera Lubrica and Pseudorhizoclonium and reinstate Acrocladus and Willeella.

The study is also an interesting example of the nomenclatural problems caused by discrepancies between morphology-based and DNA-based classifications in algal groups with a simple habit. If the nomenclatural rules were strictly adhered to, only a single species would remain in Chaetomorpha (the generitype C. melagonium (F. Weber \& D. Mohr) Kützing), and all other species would need to be transferred to a different genus. We find that the authors make a sensible decision to avoid such a nomenclatural 'earthquake' and propose to conserve Chaetomorpha against its type in a future publication (transferring C. melagonium to a new genus).

Besides taxonomic advances, the study also contributes new insights into the evolutionary history of the Cladophoraceae, showing that there have been at least three independent switches between branched and unbranched morphologies, and that the family has colonized freshwater environments on two separate occasions. This highlights the morphologically and physiologically dynamic nature of these algae, which has likely been the basis of their evolutionary success.

Although this study represents a model for the establishment of natural taxonomic classifications, the methods used here may not yield similarly conclusive results for other algal groups. A serendipitous aspect of the study is that just two molecular markers yielded a robust phylogeny of the group, with high support for most internal branches (see Figure 2). It was this well-supported backbone that allowed the new classification to be built, but in many other algal taxa two markers will not be sufficient to obtain an equally robust phylogeny, especially in poorlyknown groups for which taxon sampling is sparse (see, for example, a similarly well-designed study by Fučikova et al. (2014a) that could not completely resolve the phylogeny of the Sphaeropleales despite using seven concatenated markers). For many groups, obtaining robust phylogenies will require combining multiple markers from different cell compartments and a similarly extensive taxon sampling, which may be hard to achieve in the case of small-sized or morphologically cryptic algae. 
The Cladophoraceae are now better organized taxonomically, but they offer plenty more challenges. An interesting point for those not familiar with the systematics of Cladophoraceae, is that the study of Boedeker et al. (2016) is the first one to present a phylogeny of the family based on more than one marker. In an era in which it is normal to see algal phylogenies based on many markers or, more and more often, whole organellar genomes, this may appear strange. In particular, it seems odd that slow-evolving plastid markers which are popular for phylogenetic inference and DNA barcoding in green algae ( $r b c \mathrm{~L}$, tufA, atp A, $p s a \mathrm{~A}, p s a \mathrm{~B}, p s b \mathrm{~A})$ have not yet been sequenced for the Cladophoraceae. For reasons that are still unknown, the amplification of these "easy target" plastid markers in the Cladophoraceae has been an almost insurmountable challenge, with only one $r b c \mathrm{~L}$ sequence published thus far (for Chaetomorpha valida (J.D. Hooker \& Harvey) Kützing, Deng et al. 2014). In molecular phylogenies, this sequence is highly divergent from those of other Ulvophyceae (Fučikova et al. 2014b) and it should be confirmed based on additional data.

Presumably the amplification of plastid markers in these algae must be prevented by some atypical features of the plastid genome. The structure of the plastid genome remains one of the most mysterious and intriguing aspects of this group. This is suggested in part by the presence of actively transcribed plasmid-like DNA that seems to have derived from plastid DNA (LaClaire et al. 1998). The challenge will be to characterize these plasmids and their role in the biology of these algae, and this knowledge will contribute to our understanding of the genetic and physiological features that have made the Cladophoraceae such an adaptable and successful group.

Placement at higher taxonomic levels has also been a source of uncertainty and cannot be considered fully settled yet. At the ordinal level, Cladophoraceae belong to the order Cladophorales, a group that includes several lineages with rather different habits, but generally well supported in molecular phylogenies and defined by the unifying character of having multinucleate cells with nuclei arranged in regularly spaced cytoplasmic domains (siphonocladous organization; Leliaert et al. 2012). At the class level, Cladophorales have been generally placed in the Ulvophyceae as defined by Mattox \& Stewart (1984). However, van den Hoek et al. (1995) considered the cladophoralean algae distinctive enough to deserve a higher status and erected the class Cladophorophyceae. In recent years, most authors have preferred their classification as an order in the Ulvophyceae, supported by the fact that molecular phylogenies based mainly on nuclear markers recovered the Ulvophyceae as a monophyletic group (López-Bautista \& Chapman 2003, Cocquyt et al. 2010) in which the Cladophorales were robustly placed. However, studies based mainly on plastid DNA did not provide strong support for the monophyly of the Ulvophyceae, and recent large-scale phylogenies based on plastid multigene data do not support a monophyletic Ulvophyceae (Fučikova et al. 2014b). Needless to say, the Cladophorales, due to the difficulty of 
amplifying chloroplast markers, have not been well-incorporated into such chloroplast phylogenomic studies. Depending on future developments in the classification of the core chlorophytes (cf. Fučikova et al. 2014b), the class-level placement of the Cladophorales may have to be revised, and the possibility that the class Cladophorophyceae of van den Hoek et al. (1995) may eventually be resurrected should not be discounted.

In an era in which algal genomics has taken off, it is also worthy to note that genomic data from the Cladophoraceae are still in great shortage and limited to metagenomic data. This is unfortunate, especially because genomic information, in combination with additional physiological and biochemical studies, would greatly help clarify the processes regulating morphogenesis in these algae and further explain the basis of their phenotypic plasticity. We hope that more work will be carried out on these aspects of the biology of the Cladophoraceae and we remark that, even after more than two centuries of studies, this group still provides a wealth of opportunities for creative and exciting research.

We thank Christian Boedeker for feedback on the manuscript. Financial support during the preparation of this manuscript came from the Università Politecnica delle Marche and the Australian Biological Resources Study (RFL213-08).

\section{FABIO RINDI}

Dipartimento di Scienze della Vita e dell'Ambiente, Università Politecnica delle Marche, Via Brecce Bianche, 60131 Ancona, Italy

e-mail: f.rindi@univpm.it

\section{HEROEN VERBRUGGEN}

School of BioSciences, University of Melbourne, Victoria 3010, Australia

e-mail: heroen.verbruggen@gmail.com

\section{REFERENCES}

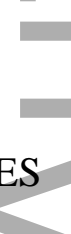

Bakker, F. T., Olsen, J. L., Stam, W. T. \& van den Hoek, C. 1994. The Cladophora complex (Chlorophyta): new views based on 18S rRNA gene sequences. Mol. Phylogen. Evol. $3: 365-82$. 
Boedeker, C. Leliaert, F. \& Zuccarello, G. 2016. Molecular phylogeny of the Cladophoraceae (Cladophorales, Ulvophyceae), with the resurrection of Acrocladus Nägeli and Willeella Børgesen, and the description of Lubrica gen. nov. and Pseudorhizoclonium gen. nov. J. Phycol.

Cocquyt, E., Verbruggen, H., Leliaert, F. \& De Clerck, O. 2010. Evolution and cytological diversification of the green seaweeds (Ulvophyceae). Mol. Biol. Evol. 27:2052-61.

Deng, Y., Zhan, Z., Tang, X., Ding, L. \& Duan, D. 2014. Molecular cloning and expression analysis of $r b c \mathrm{~L}$ cDNA from the bloom-forming green alga Chaetomorpha valida (Cladophorales,Chlorophyta). J. Appl. Phycol. 26:1853-1861.

Fučíková, K., Leliaert, F., Cooper, E. D., Škaloud, P., D'hondt, S., De Clerck, O., Gurgel, C. F. D., Lewis, L. A., Lewis, P. O., Lopez-Bautista, J. M., Delwiche, C. F. \& Verbruggen H. 2014b. New phylogenetic hypotheses for the core Chlorophyta based on chloroplast sequence data. Front. Ecol. Evol. 2: 63.

Fučíková, K., Lewis, P.O. \& Lewis, L. A. 2014a. Putting incertae sedis taxa in their place: a proposal for ten new families and three new genera in Sphaeropleales (Chlorophyceae, Chlorophyta). J. Phycol. 50:14-25.

Guiry, M. D. \& Guiry, G. M. 2016. AlgaeBase. World-wide electronic publication, National University of Ireland, Galway. http://www.algaebase.org; searched on 4 July 2016.

Hanyuda, T., Wakana, I., Arai, S., Miyaji, K., Watano, Y. \& Ueda, K. 2002. Phylogenetic relationships within Cladophorales (Ulvophyceae, Chlorophyta) inferred from 18S rRNA gene sequences, with special reference to Aegagropila linnaei. J. Phycol. 38:564-71.

Hughey, J.R., Gabrielson, P.W., Rohmer, L., Tortolani, J., Silva, M. Miller, K. A., Young, J. D., Martell, C. \& Ruediger, E. 2014. Minimally destructive sampling of type specimens of Pyropia (Bangiales, Rhodophyta) recovers complete plastid and mitochondrial genomes. Sci. Rep. 4: 5113.

La Claire, J. W., Loudenslager, C. M. \& Zuccarello, G. C. 1998.Characterization of novel extrachromosomal DNA from giant celled marine green algae. Curr. Genet. 34:204-211.

Leliaert, F. \& Boedeker, C. 2007. Cladophorales. In Brodie, J., Maggs, C. A. \& John, D. [Eds.] Green Seaweeds of Britain and Ireland. Natural History Museum Publications, London, U.K., pp. 131-183.

Leliaert, F., Rousseau, F., de Reviers, B. \& Coppejans, E., 2003. Phylogeny of the Cladophorophyceae (Chlorophyta) inferred from partial LSU rRNA gene sequences: is the recognition of a separate order Siphonocladales justified? Eur. J. Phycol. 38:233-46. 
Leliaert, F., Smith, D. R., Moreau, H., Herron, M. D., Verbruggen, H., Delwiche, C. F. \& De Clerck, O. 2012. Phylogeny and molecular evolution of the green algae. Crit. Rev. Plant Sci. 31:1-46.

Lopez-Bautista, J. M. \& Chapman, R. L. 2003. Phylogenetic affinities of the Trentepohliales inferred from small-subunit rDNA. Int. J. Syst. Evol. Microbiol. 53:2099-106.

Mattox, K. R. \& Stewart, K. D. 1984. The classification of the green algae, a concept based on comparative cytology. In Irvine, D. E. G. \& John, D. M. [Eds.] Systematics of the Green Algae. Academic Press, London \& Orlando, pp. 29-72.

van den Hoek, C. 1963. Revision of the European species of Cladophora. Brill E.J., Leiden, Netherlands, 248 pp.

van den Hoek, C., Mann, D. G. \& Jahns, H. M. 1995. Algae. An Introduction to Phycology. Cambridge University Press, Cambridge, UK, 623 pp.

van Oppen, M. J. H., Klerk, H., Olsen, J. L. \& Stam, W. T. 1996. Hidden diversity in marine algae: some examples of genetic variation below the species level. J. Mar. Biol. Assoc. U.K. $76: 239-42$

Verbruggen, H. 2014, Morphological complexity, plasticity, and species diagnosability in the application of old species names in DNA-based taxonomies. J. Phycol. 50:26-31.

Zulkifly, S. B., Graham, J .M., Young, E. B., Mayer, R. J., Piotrowski, M. J., Smith, I. \& Graham, L. E. The genus Cladophora Kutzing (Ulvophyceae) as a globally distributed ecological engineer. J. Phycol. 49:1-17.

\section{FIGURE LEGEND}

Fig. 1. Habit of selected representatives of Cladophoraceae. (A) Acrocladus herpesticus. (B) Willeella ordinata. (C) Chaetomorpha antennina. (D) Cladophora sp.

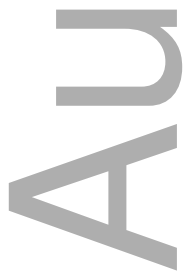




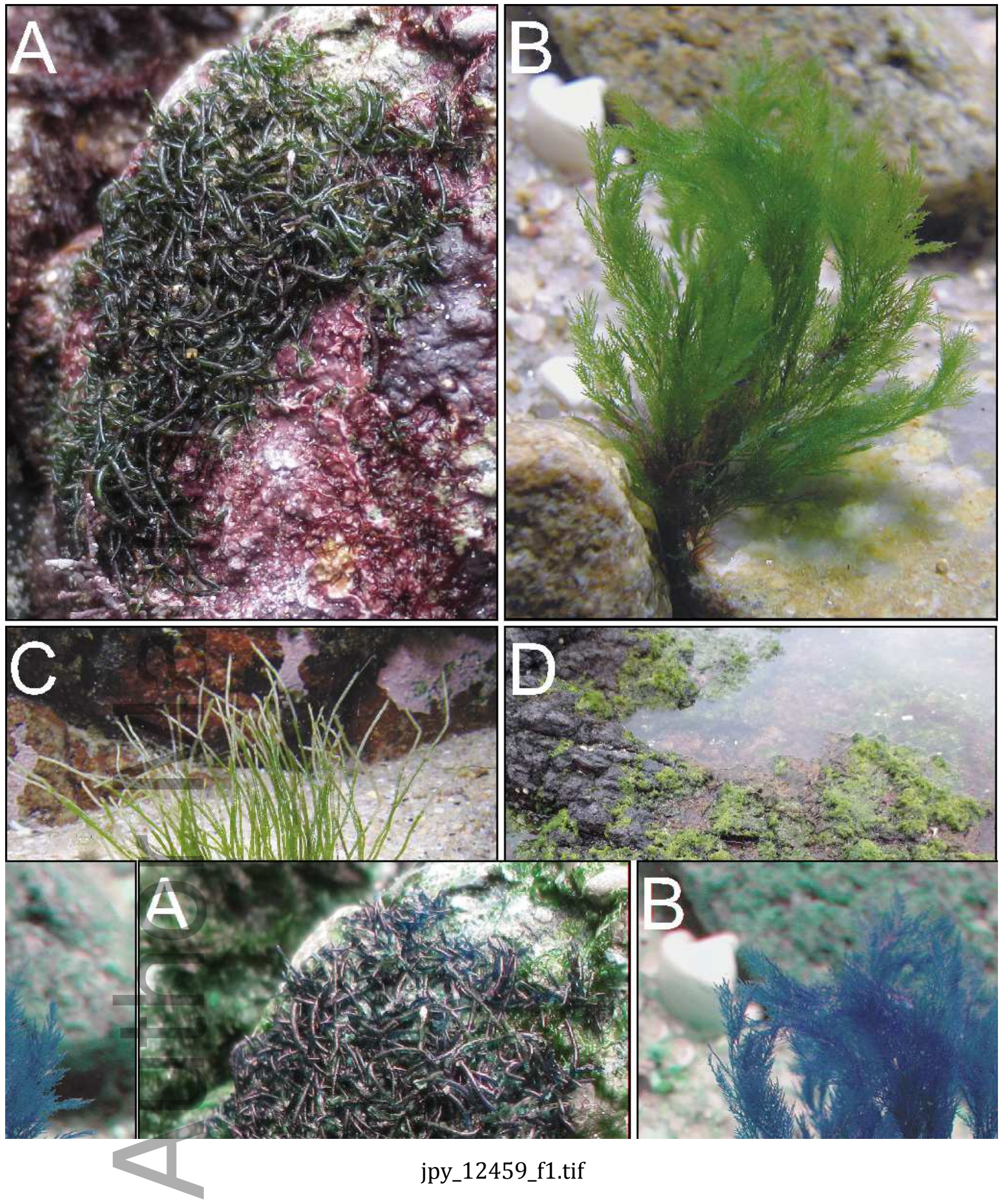

This article is protected by copyright. All rights reserved 


\section{University Library}

\section{- M M I E E R VA A gateway to Melbourne's research publications}

Minerva Access is the Institutional Repository of The University of Melbourne

Author/s:

Rindi, F; Verbruggen, $\mathrm{H}$

Title:

TAXONOMIC RESHUFFLING OF THE CLADOPHORACEAE

Date:

2016-12-01

Citation:

Rindi, F. \& Verbruggen, H. (2016). TAXONOMIC RESHUFFLING OF THE

CLADOPHORACEAE. JOURNAL OF PHYCOLOGY, 52 (6), pp.901-904. https:// doi.org/10.1111/jpy.12459.

Persistent Link:

http://hdl.handle.net/11343/292193 